\title{
A New Method of the Production of the THZ Electromagnetic Wave and Electromagnetic Paticle's Flows and Other Application*
}

\author{
Ye Yin', Lun Fei², Youngqiang Zhu'², Chun Jeff', Shi Huang', Shen Xia ${ }^{2}$ \\ ${ }^{1}$ The College of Information, Mechanical and Electrical Engineering, Shanghai Normal University, Shanghai, \\ China \\ ${ }^{2}$ The Shanghai Shguhuang Particle's Flows Science and Technology Company, Shanghai, China \\ Email: zhuyq@fudan.edu.cn
}

Received 21 July 2014; revised 10 August 2014; accepted 18 August 2014

Copyright (C) 2014 by authors and Scientific Research Publishing Inc.

This work is licensed under the Creative Commons Attribution International License (CC BY). http://creativecommons.org/licenses/by/4.0/

(c) (i) Open Access

\section{Abstract}

This paper reveals that a new method of the production of the THZ electromagnetic wave and electromagnetic particle's flows is using a solid-consisted body, and the solid-consisted body is formed of the polylayer's parallel nonferromagnetic knitted conductance's nets: when a large powered (around $1000 \mathrm{~W}$ ) microwave $(2.45 \mathrm{G})$ once comes into the solid-consisted body, a change from microwave to electromagnetic particle's flows takes place and it does not have a place-phase of the wave by its reflection and transmission between net and other net limitless times; and when the surface-induction's current produces the electron's transition in the net-holes, the THZ electro-magnetic wave is produced, and the THZ electromagnetic wave is divided into two parts: single frequency and continuous spectrum. When the THZ electromagnetic wave and the electromagnetic particle's flows illuminate the living beings, the living beings will live better.

\section{Keywords}

Knitted Conducted Net, $\mathrm{TH}_{\mathrm{z}}$ Electromagnetic Wave, Electromagnetic Particle's Flows, Live Better

\section{Introduction}

$\mathrm{TH}_{\mathrm{Z}}$ electromagnetic wave is mystical electromagnetic wave band which is hundreds or thousands of times higher than the frequency band $(2.45 \mathrm{G})$ of the microwave stove, but this band is lower than the frequency band

\footnotetext{
"Notes: This research work got a subsidization from the shanghai science and technology committee. The number of the subsidization-task is 1304H161400.

How to cite this paper: Yin, Y., Fei, L., Zhu, Y.Q., Jeff, C., Huang, S. and Xia, S. (2014) A New Method of the Production of the THZ Electromagnetic Wave and Electromagnetic Paticle's Flows and Other Application. Natural Science, 6, 1186-1196. http://dx.doi.org/10.4236/ns.2014.614106
} 
of super far infrared ray of a cup of the hot water in $80^{\circ} \mathrm{C}$ around $2.4 \mathrm{~T}(2400 \mathrm{G})$. The power of the microwave stove can do larger than $1000 \mathrm{~W}$, but its frequency can't do higher; and the power of the high-temperature body's infrared ray is lower. Therefore, how do we get a frequency band between the two frequency band and how do we get a large power of the frequency band wave? $\mathrm{To}$ get $\mathrm{TH}_{\mathrm{Z}}$ electromagnetic wave with a large power is very difficult. There isn't the wave band in nature. This waveband is called "quiet-music wave band".

At present people use the higher intensity laser pulse to polarize air [1]-[4], or in the accelerator let the electrons do higher frequency electromagnetic oscillation [5], and let some special polyhole's material be hot and thus it produces those lower power THZ electromagnetic waves. But the THZ electromagnetic wave has many wider applications on the living being, the medicine, the agriculture, the survey and the correspondence: the energy of the THZ electromagnetic wave is corresponding to the hydrogen $(\mathrm{H})$ bond in the chain structure of the water molecule; the energy of the THZ electromagnetic wave is very close to the spinning energy level and vibration energy level of the large molecule of the living beings; and the energy of the THZ electromagnetic wave is absorbed and transmitted differently by different materials; thus it can become a new sounder......[6]-[8].

The electromagnetic particle's flows without wave motion character are not brought into being in the nature, because in nature both light and electromagnetic wave have wave-motion characteristics such as interference and diffraction, and when their frequency is higher there is particle's characteristic such as light-electricity effect and Kangpudwn scattering. But microwave reflects and transmits limitless times between many polylayer's parallel nonferromagnetic knitted conductance's nets and it changed to electromagnetic particle's flows without a place-phase of the wave: for one thing it produces energy's field and hots material, for another thing it can't be surveyed generally, and people don't discover such power with an oscilloscope. The electromagnetic particle's flows will make wide applications on the living being, the medicine, the agriculture and the industry.

\section{A New Method of the Production of the $\mathrm{TH}_{\mathrm{z}}$ Electromagnetic Particle's Flows}

This paper reveals that the key technology is a "change machine" that can change $2.45 \mathrm{G}$ microwave to electromagnetic particle's flows and $\mathrm{TH}_{\mathrm{Z}}$ electromagnetic wave.

\subsection{The Structure of the "Change Machine"}

According to Figure 1, the key department of the change machine is a solid consisted body (12 layers) of the knitted copper net (100 item), the area of every layer is $20 \mathrm{~cm} \times 16 \mathrm{~cm}$, every layer of the copper nets all is fixed by the copper support, the distance between layer and layer is $1.5 \mathrm{~cm}$, and in four circumference it is winded two layer of the copper nets.

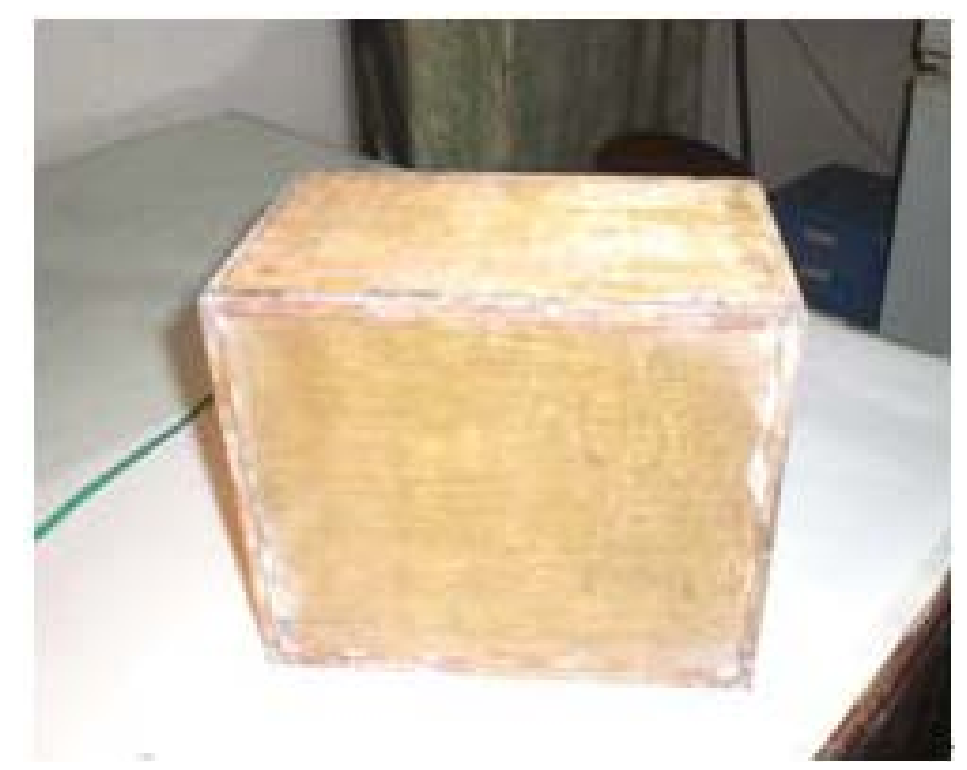

Figure 1. The grid net of the three-dimension conducted body. 


\subsection{How Does It Produce the Electromagnetic Particle's Flows?}

When the microwave in $\mathrm{z}$ direction comes vertically into the solid consisted body of the copper nets that is insulated at the place in question, because the solid consisted body of the copper nets has oneself distributed electric capacity and the distributed electric capacity to the around casing, in this case, the electric vector E of the X-Y direction of the microwave (according to MAIKESIWEI electromagnetic equations) can be uninterrupted to charge and discharge cycle at the surface of the knitted copper nets (in the X-Y direction).

Peoples can't help asking: when the microwave comes vertically into the surface of the first-lager copper net, what have happened to all the reflection? If people look the knitted copper nets as an electricity conductor, according to the count, formula of the depth of the tending towards skin of the conductor's surface of the electromagnetic wave is: $\delta=(1 /(\pi f \mu \sigma))^{1 / 2}$.

In the case, to copper $\sigma=7 \times 10^{7} / \Omega, \mu=4 \pi \times 10^{-7} \mathrm{H} / \mathrm{m}, \mathrm{f}=2.45 \times 10^{9}$, it got the transmission's thickness $\delta=$ $1.22 \times 10^{-3} \mathrm{~mm}$, therefore when looking that the thickness of the 100 item knitted copper net is much larger than the transmission's thickness $\delta$, people can't help suspecting: Can the microwave transmit?

To observe the knitted copper net with a microscope, people can discover that it is not a plane structure and it is a three dimension's solid structure, in addition there is specific contact's resistance between net silk and net silk, in this case when the microwave leads the surface's induced current $\mathrm{J}$ on the knitted copper net, the $\mathrm{J}$ is divided into limitless very small branches $(\mathrm{J})_{\mathrm{i}}$ flowing along the net silks, in the flowing process the $(\mathrm{J})_{\mathrm{i}}$ can flow to the opposite surface of the first-layer of the solid consisted body of the copper nets, in addition, in this flowing process it is produced that the microwave can transmit to the solid consisted body of the copper nets at the same time. If there is larger contact's resistance between net silk and net silk, the transmission coefficient is larger, for this reason, the knitted copper nets can't be drawn tightly, and the knitted copper nets must be in the neater and limper case.

According to a rough estimating, suppose the probability of the flowing (J)i along the net silk is $1 / 4$ and the probability of the transmission also is $1 / 4$, thus the $3 / 4$ of the microwave is reflected back by the first layer copper net, then the $3 / 4$ is reflected by the fuselage's emit-opening, and then the $3 / 4$ of the microwave both is lighting up the first lager copper net, and both the $1 / 4$ of the $3 / 4$ is transmitted to the solid consisted body......, after many rounds the microwave all entered to the solid consisted body of the copper nets. In this process the transmitted microwave also starts the reflection and transmission in the second layer copper net, and starts the reflection and transmission in the third layer copper net. Because the $2.45 \mathrm{G}$ microwave's wavelength equals $\mathrm{c} / \mathrm{f}=3 \times$ $10^{10} \mathrm{~cm} / 2.45 \times 10^{9}=12.24 \mathrm{~cm}$, and the half of the wavelength is $6.12 \mathrm{~cm}$, across the reflection of the fourth copper net, the reflected back microwave may have a place-phase difference $\pi$, for this reason the transmissions and the reflections of the different layers are mixed with each other, in this case electromagnetic waves with limitless different place-phases are mixed in a limited area, and they must become the electromagnetic particle's flows without a place-phases of the wave.

\subsection{How Does It Produce the Single Frequency $\mathrm{TH}_{\mathrm{z}}$ Electromagnetic Wave?}

To observe a hole's structure of the 100 item knitted copper net with a microscope, it is shown as Figure 2.

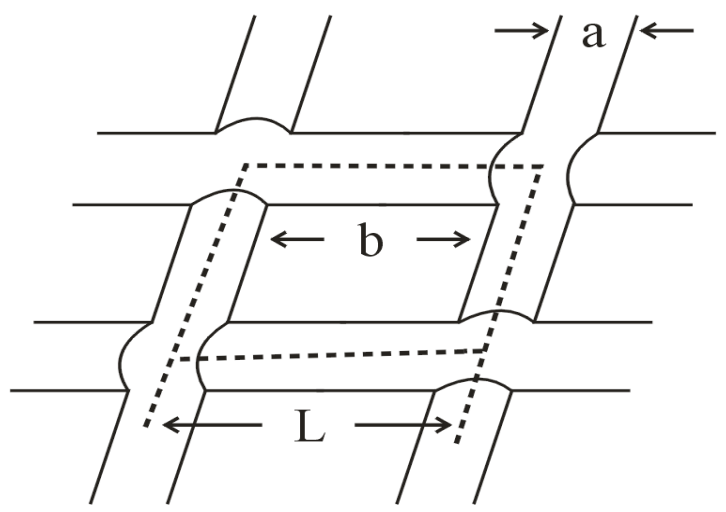

Figure 2. A hole's structure of the 100 item knitted copper net. 
The part in the dotted line becomes a unit $\mathrm{L}$ of the 100 item knitted copper net, in the unit $\mathrm{L}$ there is a centre hole whose side length is $\mathrm{b}$, and around it there is the half-section of the this copper silk, the diameter $\mathrm{D}$ of the copper silk is a. To 100 item copper net, the side length of the unit $L$ equals $L$ and $L=0.17 \mathrm{~mm}$, the side length of the centre hole $=0.085 \mathrm{~mm}$, and around the centre hole there is the half-section of the thin copper silk. After the function of the $2.45 \mathrm{G}$ microwave, to a unit $\mathrm{L}$ of the solid consisted body of the knitted copper nets, the place-phase of the microwave of the reception of the obverse side of the unit $L$ is different with the place-phase of the microwave of the reception of the reverse side of the unit L, thus between the observe and reverse direction of the centre hole of the knitted copper net, there is an instantaneous potential difference, at this time the centre-hole b becomes a cavity of the electromagnetic oscillation. As a result of the edge's action, the length of the cavity of the electromagnetic oscillation must be far smaller than the length of the diameter $\mathrm{D}(0.085 \mathrm{~mm})$ of the thin copper silk, its section figure is shown in Figure 3, by a rough estimating to the length $\mathrm{X}$ of the resonant cavity, it is about the $1 / 3$ of the diameter of the thin copper silk, so $X=0.03 \mathrm{~mm}=0.003 \mathrm{~cm}$.

Suppose in the surface and inside of the copper silk the total length of the resonant cavity is roughly three times of the $0.003 \mathrm{~cm}$, in that way the resonant frequency can be counted according to formula $\mathrm{f}=\mathrm{n} \cdot(\mathrm{c} /(3 \mathrm{x}))$, in that case $\mathrm{c}$ is light-velocity and $\mathrm{n}$ is a resistance's factor of the copper silk (it makes the light-velocity slower inter copper silk).

Suppose $\mathrm{n}=0.3$, then the once frequency is $0.3 \times\left(3 \times 10^{10} \mathrm{~cm} / \mathrm{s}\right) \times(3 \times 0.003 \mathrm{~cm})=1 \times\left(10^{12}\right) / \mathrm{s}=1 \mathrm{TH}_{\mathrm{z}}$; the double frequency is $2 \mathrm{TH}_{\mathrm{z}}$; the three times frequency is $3 \mathrm{TH}_{\mathrm{z}}$. According to MAIKESIWEI energy's distributive law, the rate of these powers is $1: \mathrm{e}^{-2}: \mathrm{e}^{-3}$, so the rate approximates $1: 1 / 6.45: 1 / 17.61$; the rate of these peaks is radical expression and is roughly $1: 1 / 2.5: 1 / 4.2$, this count doesn't differ the figure-spectrum that is measured by VERTEX80V-model far infrared ray spectrum appearance of the Germany BRUKER company, the experimental figure-spectrum curve is as Figure 4.

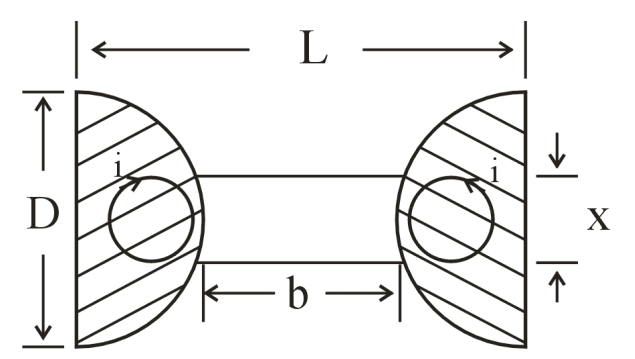

Figure 3. The transverse section of a centre hole (i is oscillated current-ring).

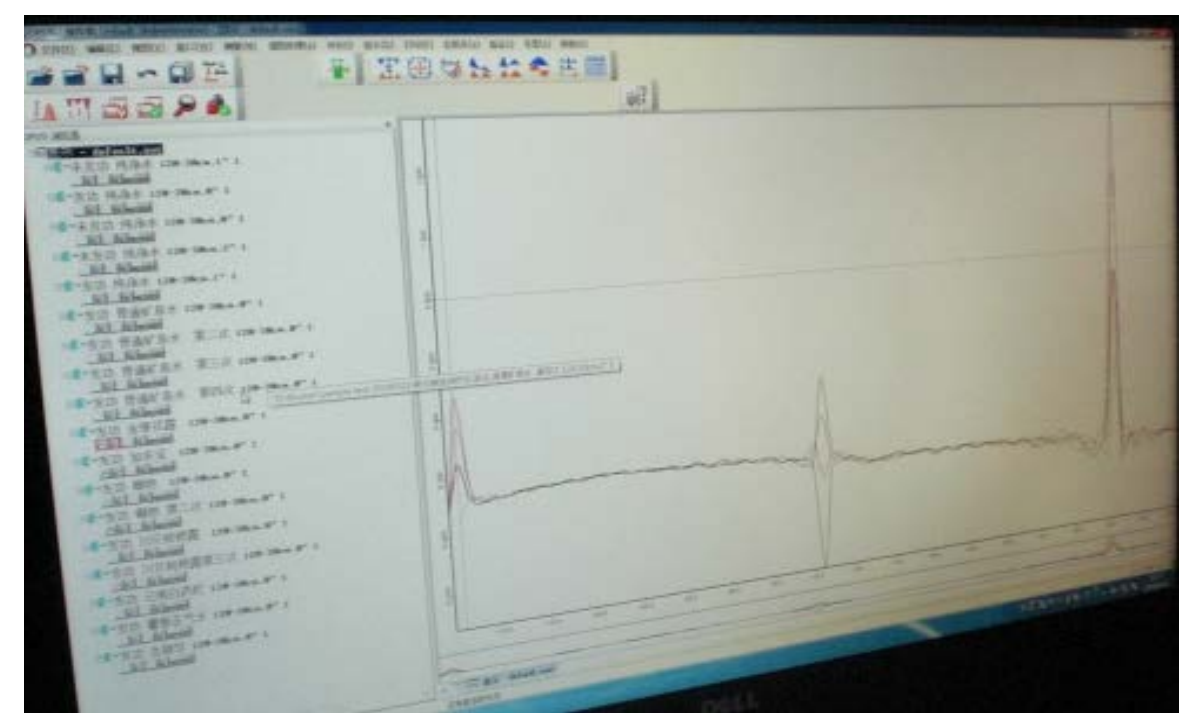

Figure 4. The figure-spectrum of the THZ frequency (f1 = 1.2 THZ; f2 = 2.4 THZ; f3 = 3.6 THZ, I1:I2:I3 = 1:1/3:1/4). 


\subsection{How Does It Produce the $\mathrm{TH}_{\mathrm{Z}}$ Continuous Wave?}

In above subhead, this paper shows the THZ single wave is produced in the half-section of the thin copper silk around the net's mouth of the 100 item knitted copper net, then the THZ continuous wave is produced in the induced current Ji that is flowing in the thin copper silk of the 100 item knitted copper net, as Figure 2 shows, when on the $\mathrm{X}-\mathrm{Y}$ plane the induced current $\mathrm{Ji}$ is flowing in a thin copper silk, because in the $\mathrm{z}$ direction of the joint-point of the net's hole there is a embossing, so the induced current Ji will produce a THZ wave with specific wavelength this time flowing across a embossing.

Suppose a single $2.45 \mathrm{G}$ microwave produces induced current $\mathrm{J}$ in the surface (X-Y plane) around $2.5 \mathrm{~cm}$ of the knitted copper net, in a period it goes total distance meaning $2.5 \mathrm{~cm} \times 2=5 \mathrm{~cm}$. To 100 item knitted copper net the every unit of the net hole is about $0.17 \mathrm{~mm}$, how many embossing the surface induced current Ji goes totally across? $\mathrm{N}=5 \mathrm{~cm} / 0.017 \mathrm{~cm}=294$, in this case the surface current produces the THZ wave which frequency is $2.45 \mathrm{G} \cdot 294=720 \mathrm{G}=0.72 \mathrm{~T}$ in every embossing (in this case the wavelength of the $2.45 \mathrm{G}$ microwave is about $10 \mathrm{~cm}$, the induced current Ji goes a distance of the knitted copper net's surface in a period, and the distance is about $1 / 2$ of the wavelength, so the distance is as $5 \mathrm{~cm}$ ).

Because in knitted conduct's net the surface induced current Ji is affected by surroundings and direction, in a period the range that the surface induced current Ji goes through isn't defined, for this reason, the frequency of the THZ continuous wave is produced by the thin copper silk of the knitted copper net of the "change machine", and the frequency is continuously changed in a range.

With Germany Bruker Company VERTHX80V-model beyond infrared red spectrum mater to measure the range of the $\mathrm{TH}_{\mathrm{Z}}$ continuous wave, the result is shown in Figure 5.

Because being of the wire resistance of the knitted copper silk, the "change machine" produces the power of the $\mathrm{TH}_{\mathrm{z}}$ continuous wave far smaller than the power of the single frequency $\mathrm{TH}_{\mathrm{z}}$ wave, the rate coefficient is roughly $1 / 10$, therefore the power of the $\mathrm{TH}_{\mathrm{Z}}$ continuous wave can nearly be neglected.

\subsection{The Energy Rate between the $\mathrm{TH}_{\mathrm{Z}}$ Wave and the Electromagnetic Particle's Flows}

According the electromagnetic theory to count the energy rate between the $\mathrm{TH}_{\mathrm{Z}}$ wave and the electromagnetic particle's flows, it equals to the rate between the area of the centre hole and the area of the surrounding half-section of the copper silk, by comparing it is $1 / 4: 3 / 4$, therefore the energy of single frequency wave and the $\mathrm{TH}_{Z}$ continuous wave is the $1 / 4$ of the import microwave power, and other $3 / 4$ energy is being by the form of the $\mathrm{TH}_{\mathrm{Z}}$ electromagnetic particle's flows.

In order to prove that above mentioned judge is correct, it is needed with an experiment, thus the authors take a large container and send into the instrument, this container is shown in Figure 6. The container is formed of surrounding iron sheet; there are concentrated small-holes $(\varphi 1 \mathrm{~mm})$ on the iron sheet, and the interval dis-

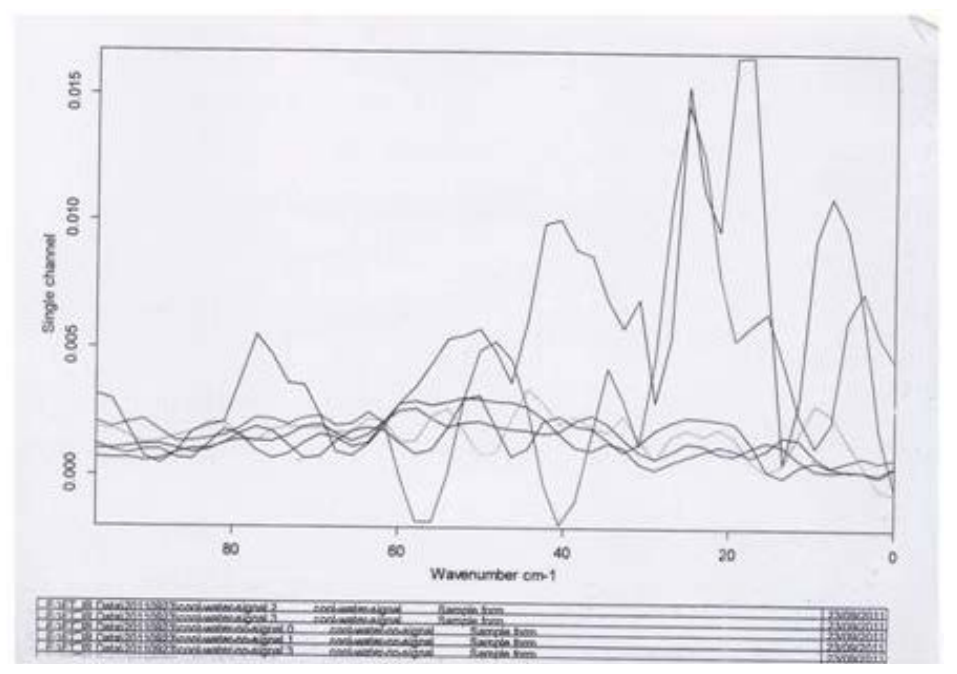

Figure 5. The frequency range of the THZ continuous wave (300 G - $900 \mathrm{G})$, the centric frequency is $600 \mathrm{G}$, centre frequency $\mathrm{f}=($ wavenumber $/ \mathrm{cm}) \cdot\left(3 \times 10^{10} \mathrm{~cm} / \mathrm{s}\right)$. 


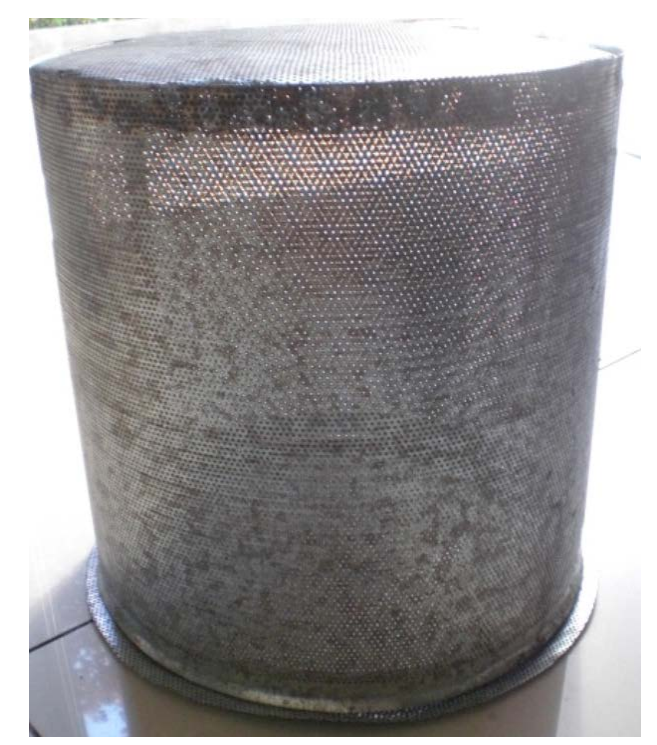

Figure 6. The installation of the sealed iron sheet with concentrated small-holes $(\varphi 1 \mathrm{~mm})$ (the diameter is $25 \mathrm{~cm}$, the high length is $30 \mathrm{~cm}$ ).

tance between a small hole and the near small hole is about $1 \mathrm{~mm}-1.5 \mathrm{~mm}$. The above-mentioned installation is only opened for $\mathrm{TH}_{\mathrm{Z}}$ wave and is not opened for electromagnetic particle's flows. When the instrument heats the $500 \mathrm{ml}$ water in a beaker without the container, the risen temperature is 4 degrees, and when the instrument heats the $500 \mathrm{ml}$ water in a beaker into the container, the risen temperature is 1 degree. It proves that the above-mentioned judge is very correct.

\section{3. $\mathrm{TH}_{\mathrm{Z}}$ Wave and Electromagnetic Particle's Flows Act on Water [9]}

\subsection{What Is Water Molecular Chain?}

Pure water or running water is being with liquid state at $0^{\circ} \mathrm{C}$ to $100^{\circ} \mathrm{C}$, because every water molecule has a polarization, as Figure 7 shows, there is a negative polarization near by the oxygen $(\mathrm{O})$ atom, and there is a positive polarization near by the hydrogen $(\mathrm{H})$ atom.

When three water molecules are together intimate, the state appeared in Figure 8.

In general, nearly hundred water molecules can be put on X direction in order to make a Long-Chain of water molecules, the long-chain of water molecules is affected by temperature, when the temperature is higher, the long length of the long-chain of water molecules is getting short after affection of the BULANG hot-motion, in this time it is easy combined with the large molecules of the living beings and the activity of the living beings is enhanced; oppositely when the temperature cuts down to $4{ }^{\circ} \mathrm{C}$, the specific gravity of the water is largest, this time the long length of the long-chain of the water molecules is longest, and the long-chain isn't combined with large molecules of living beings, and the living beings produce winter sleep (such as snake, tortoise and the other). On the surface of the water as the action of surface's tensile force resists the affection of the hot-motion, the long-chain of the water molecules is getting longer.

In the end of the water molecules chain display weak basicity $\mathrm{OH}^{-}$generally, it can help absorb the cell of the living beings, but generally when the long length of water molecules chain is longer than the length of the nearly hundred water molecules, the water molecules chain becomes a winding structure, and the living beings cells hardly absorb.

\subsection{The Pure Single Frequency $\mathrm{TH}_{\mathrm{z}}$ Wave Acts on Water Molecules Chain}

Because the energy of the $1 \mathrm{TH}_{\mathrm{Z}}$ pure single frequency electromagnetic wave corresponds to the energy of the vibration energy level and the spinning energy level of the hydrogen $(\mathrm{H})$ bond of the long water molecular chain, therefore the energy of the pure single frequency $\mathrm{TH}_{\mathrm{Z}}$ wave can change to the energy of the inside hot-energy of the long water molecular chain, the vibration model and the spinning model are shown as Figure 9. 


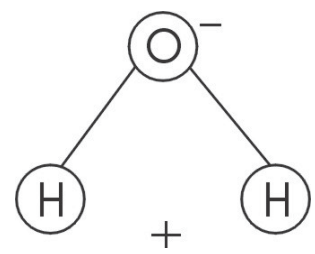

Figure 7. The polarization of a water molecule.

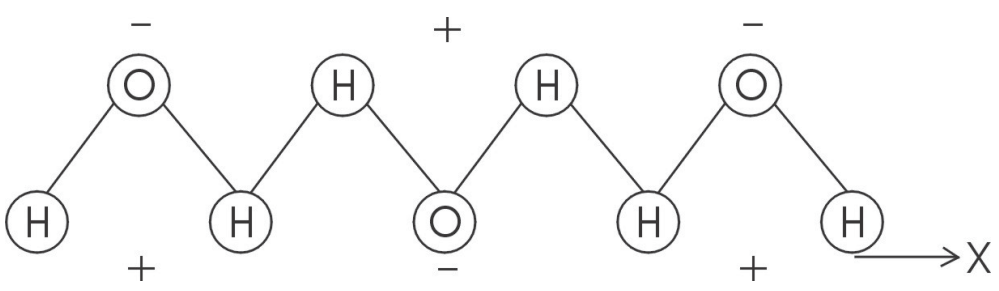

Figure 8. The intimated state of the three molecules.

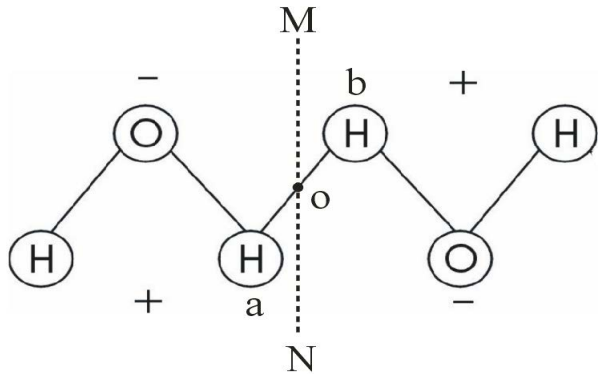

Figure 9. The vibration energy and the spinning energy of the hydrogen $(\mathrm{H})$ bond of the water molecules chain.

As Figure 9 shows, when the hydrogen atom a and the hydrogen atom b with centre $\mathrm{o}$ spot on the paper plane mutually do sport closing the straight line MN and leaving the straight line MN partly, the energy of the such reciprocal sport is the vibration energy; when the hydrogen atom a and the hydrogen atom b with centre o spot mutually do sport closing the paper plane and leaving the paper plane partly in the opposite direction, the energy of the such reciprocate sport is spinning energy, these two energies are the inside potential energy of the water molecular chain, they don't connect with the together sport of the water molecular chain, therefore they don't connect with the temperature of the water.

Using the installation of the Figure 6, after taking $200 \mathrm{ml}$ water into a beaker and taking the beaker into the installation, when a worker starts the microwave machine of the instrument, this time only the $1.2 \mathrm{~T} \mathrm{TH}_{\mathrm{Z}}$ wave can act to the $200 \mathrm{ml}$ water, the machine in every sequence works in half minute and rests in half minute, after 6 sequences the worker immediately measures the temperature of the $200 \mathrm{ml}$ water and compares with the setting temperature of the $200 \mathrm{ml}$ water before experiment, the worker will discover that the risen temperature is 0 , and it reveals that the total energy of the $1.2 \mathrm{~T} \mathrm{TH}_{\mathrm{Z}}$ wave is already changed to inside energy of the water molecules chain, but as a result of the destruction of the BULANG hot-motion of the water molecules chain, the vibration energy and the spinning energy of the hydrogen bond of the water molecular chain will be getting to send out, and they become the energy of the collective motion of the water molecular chain, in this time the temperature of the water is getting higher, the worker follows to measure the change of the $200 \mathrm{ml}$ water temperature, suppose the moment of the end of the action of the pure $\mathrm{TH}_{\mathrm{Z}}$ wave is 0 moment, the worker will discover the change of the water temperature in 5 minutes as Figure 10.

Passing around 3 minutes, the water temperature rises to the larger value that is about $3^{\circ} \mathrm{C}$, then the water temperature is cooled by air.

\subsection{The $\mathrm{TH}_{\mathrm{Z}}$ Wave and the Electromagnetic Particle's Flows Act Together on the Water}

Because the end of the long water molecular chain shows the weak alkalinity in general case, after the action of 


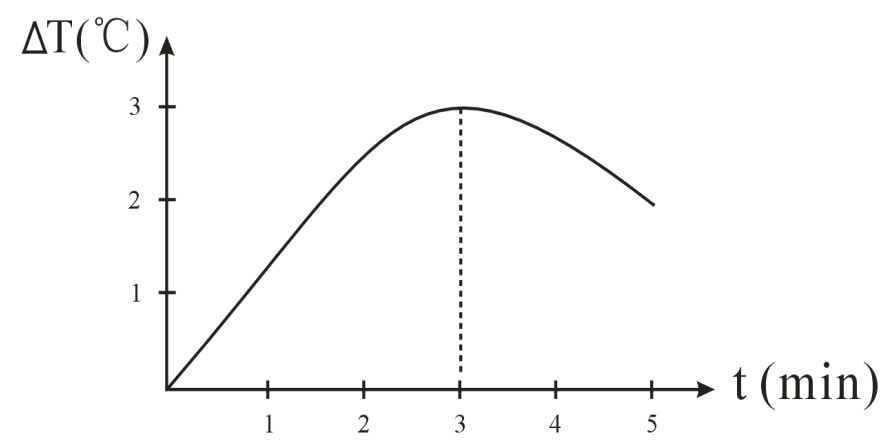

Figure 10. After action of the pure THZ wave the change of the water temperature.

the electromagnetic particle's flows the end can do different straight motion (and in microwave stove after the action of the microwave, the end of the long water molecular chain can do different curve motion below effecting of the eddy's current, this is the difference of the two cases), and at the same time the $\mathrm{H}-\mathrm{H}$ bond of the water molecules chain do the vibration motion or the spinning motion after the action of $\mathrm{TH}_{Z}$ wave, when after these action together of the $\mathrm{TH}_{\mathrm{Z}}$ wave and the electromagnetic particle's flows the $\mathrm{H}-\mathrm{H}$ bond's snap happens, and the long water molecular chain will change to shot water molecular chain.

A worker can do an experiment for reflecting above process: a beaker takes a general water for comparing, the other beaker takes the water that is together acted by the $\mathrm{TH}_{\mathrm{Z}}$ wave and electromagnetic particle's flows in 2 times (every time by these action the temperature of the water is risen to $85^{\circ} \mathrm{C}$, then the water is cooled to general temperature), then the worker takes two egg shell with empty centre (when a worker drew the egg white and the egg yellow from the egg, then the worker seals the small hole with some adhesive), and the worker takes the two egg shells to sink into the bottom of the two beakers partly, in every hour the worker measures by one time and measures the weights of the osmotic water of the egg shells partly, the worker can discover these difference.

The above dates (Table 1) show: the osmotic water of the small molecular water is stronger than the osmotic water of the general pure water, in the short start time there is ten times of the strong in two cases, as shown in Figure 11.

\section{4. $\mathrm{TH}_{\mathrm{z}}$ Wave and Electromagnetic Particle's Flows Affect the Living Cell [10]-[12]}

\subsection{The Pure $\mathrm{TH}_{Z}$ Wave Effects the Activation of the Edible Bacterium}

A handled instrument with a "changer machine" and with a microwave machine is as Figure 12 shows, in the right side of the instrument there is a glass turntable that can turn with a slow speed. If the installation of the sealed iron sheet with concentrated small-holes $(\varphi 1 \mathrm{~mm}$ ) (as Figure 6) is taken above the glass turntable, once the machine is starting, there will be the energy of the pure $\mathrm{TH}_{\mathrm{Z}}$ wave in the installation.

After the bacterium species of the XingBao mushroom is having a inoculation and grew in a bottle $2 \mathrm{~cm}$ from the bottle mouth, then every bottle will be taken into the iron sheet installation and will be handled (handle 30 seconds, rest 30 seconds, altogether 6 orders), after handling the temperature of the bottle of the nutrition base is risen for $1.5^{\circ} \mathrm{C}$, thus one day they are handled for one time, altogether they are handled for three days, in the culture room after 35 days the bacterium species already grows to bottom of the nutrition base bottle, then they are taken to a growing mushroom room whose temperature is lower, again after 15 days the XingBao mushroom can harvest, the handled XingBao mushroom and the compared XingBao mushroom are as Figure 13 shows.

The total weight of the handled 16 bottles of the XingBao mushroom is $2929.4 \mathrm{~g}$, and the total weight of the compared 16 bottles of the XingBao mushroom is $2705.6 \mathrm{~g}$, and it shows that after the activation of the $\mathrm{TH}_{\mathrm{Z}}$ wave the XingBao mushroom had increased $8.27 \%$.

\subsection{The Pure $\mathrm{TH}_{\mathrm{Z}}$ Wave and Electromagnetic Particle's Flows Together Effect the Activation of the Soybean's Seed}

Because the plant's seed accepted the effect of the heavy force of the earth, its cells can form non-symmetry in the $360^{\circ}$ space, and this non-symmetry will affect the spread of the DNA chains of the cell nucleus, when the 


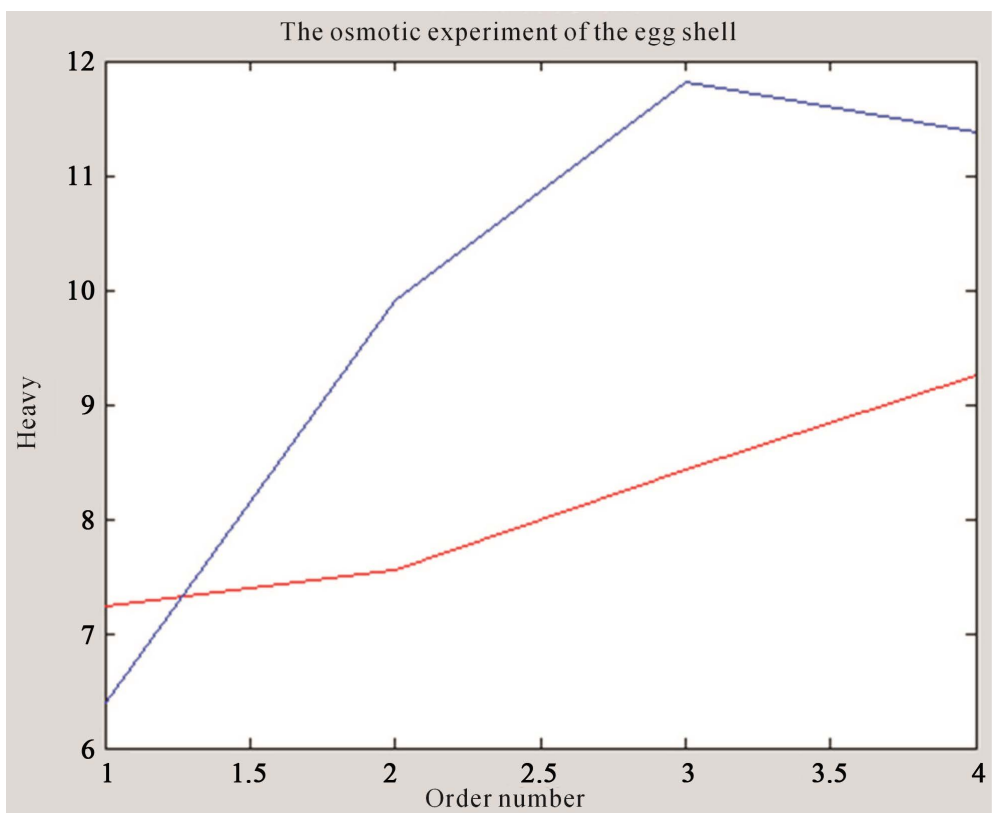

Figure 11. To measure the osmotic water of the handled water (orchid) and the general pure water (red) partly.

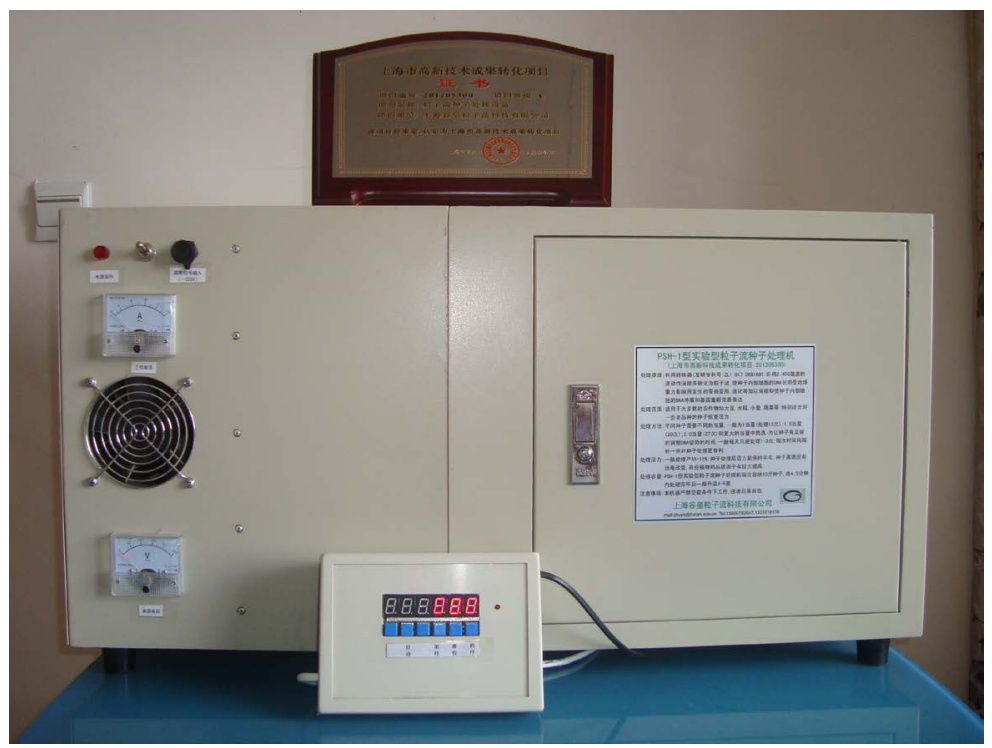

Figure 12. A handled instrument with a "changer machine" and with a microwave machine (input total power $1000 \mathrm{~W}$, the power of the $1.2 \mathrm{~T}$ pure frequency THZ wave is about $200 \mathrm{~W}$, the power of the electromagnetic particle's flows is about $600 \mathrm{~W}$ ).

Table 1. The osmotic experiment of the egg shell ( $\Delta$ value is the heavy of the osmotic water).

\begin{tabular}{ccccccc}
\hline Date & time & Temperature $\left({ }^{\circ} \mathrm{C}\right)$ & Egg shell in pure water $(\mathrm{g})$ & $\Delta$ value & Egg shell in small molecule's water $(\mathrm{g})$ & $\Delta$ value \\
\hline 3.21 & $17: 06$ & 17.4 & 7.23 & & 6.39 & \\
3.21 & $22: 04$ & 17.6 & 7.55 & 0.32 & 9.91 & 3.52 \\
3.22 & $8: 00$ & 16.4 & 8.43 & 1.20 & 11.82 & 5.43 \\
3.22 & $13: 35$ & 18.2 & 9.25 & 2.02 & 11.38 & 4.99 \\
\hline
\end{tabular}



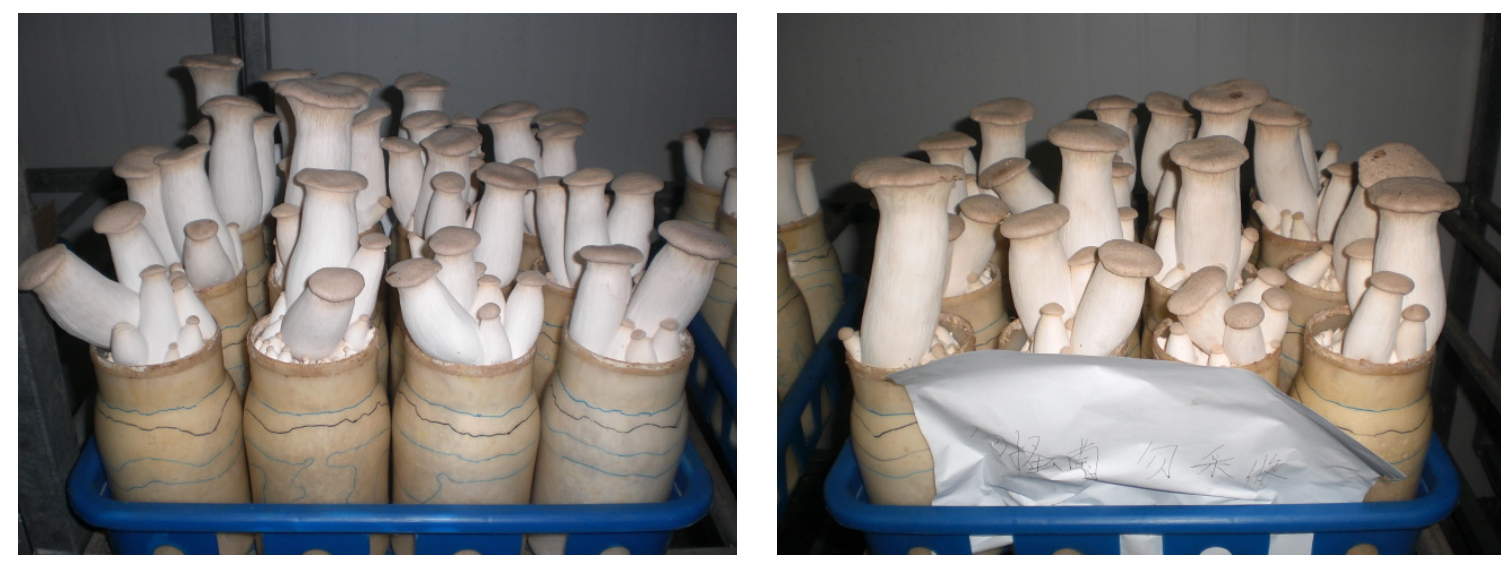

Figure 13. The handled XingBao mushroom (the left side) and the compared XingBao mushroom (the right side).

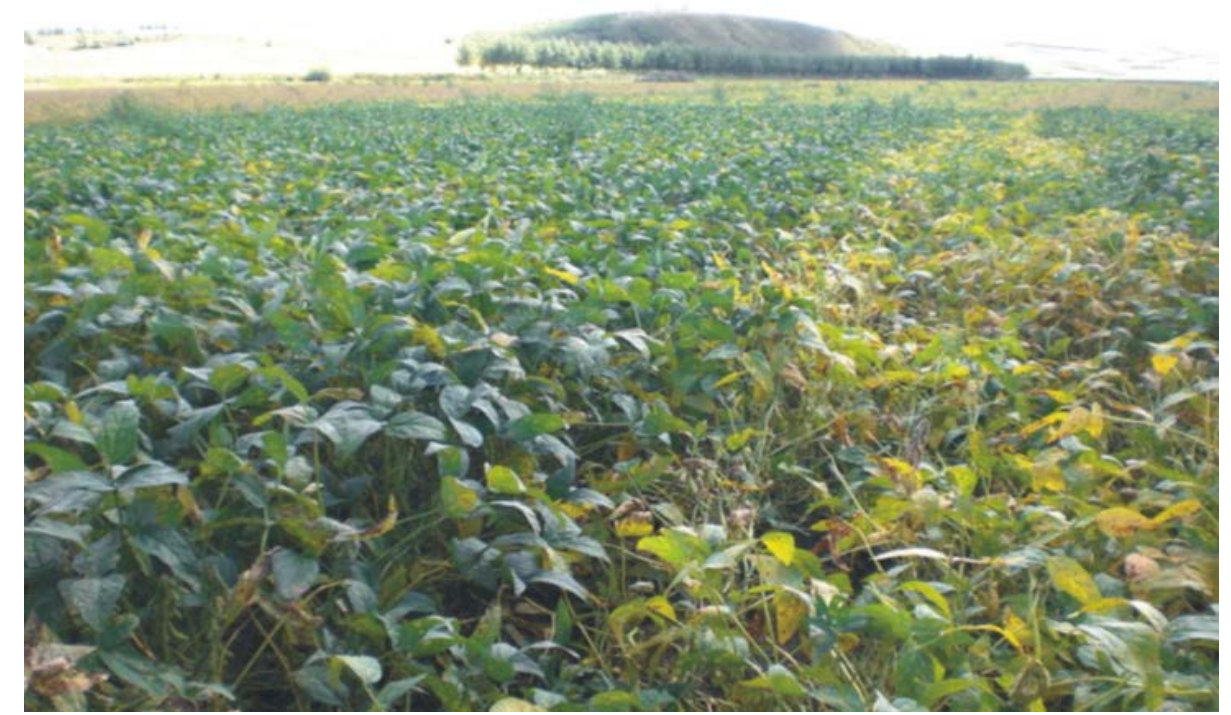

Figure 14. The comparison of the large soybean farm: left side is handled; the soybean is growing higher and is producing more.

winding of the DNA chains takes place, which then directly affect the growth and putout of the cells. In the effecting of the THZ wave and electromagnetic particle's flows in the end of the chains, repeated lash takes place in the end of the chains, then the seeds rest, and the DNA gene chain of the inside of the seed is shifting to fine posture. After resting, repeated lash takes place. After cyclical orders, the DNA chains of the inside of the seeds are resuming to finer state.

Recently, in the one order, the handled seeds are about $3.5 \mathrm{~kg}$; the temperature rise is about $4^{\circ} \mathrm{C}-5^{\circ} \mathrm{C}$; and every day there are 2 orders for the handle (the handled interval time is larger than four hours). In ten days there are 20 orders for the total handle. The comparison of the large soybean farm is shown in Figure 14.

As a result of the statistics of the soybean product of the Neimenggu China, it discovers that the average rate of increase is $10 \%-15 \%$ to many of breeds.

\section{Acknowledgements}

Extend thanks to the Shanghai science and technology committee for a subsidization to this work; Extend thanks to Wenchun Zhang of the College of the Living Science of the Jiangx Traditional Chinese Medical Science and Chinese Medicine University for a help to this work; Extend thanks to Chun Cai, yougen Chen, Jigang Chen of 
the Shanghai Shguhung particle's flows science and technology company for taking part in this work; Extend thanks to Jade It, QiaoZen It of the shanghai agricultural science academy for taking part in this work; Extend thanks to the graduate student Chuangyang Liu, Li It, Xiaojing Cui of the shanghai Normal University for taking part in this work; Extend thanks to Xiadang Yuan of the spread centre of the agricultural technology of the Neimenggu Moqi country for taking part in this work; Extend thanks to fengwu Chen of the yan bian seed management station of the Jilin province for taking part in this work; Extend thanks to Zhiming Tang of the physics Department of the Fundan University for taking part in this work; Extend thanks to the teachers of the committee for bring forth new ideas of the Shanghai Old Science Association for taking part in this work and other.

\section{References}

[1] Darrow, J.T., Hu, B.B., Zhang, X.C., et al. (1990) Subpicosecoud Electromagnetic Pulses from Large-Aperture Photoconducting Antennas. Optics Letters, 15, 323. http://dx.doi.org/10.1364/OL.15.000323

[2] Zhang, X.C., Hu, B.B., Darrow, J.T., et al. (1990) Generation of Femtosecond Electromagnetic Pulses from Semiconductor Surfaces. Applied Physics Letters, 56, 1011. http://dx.doi.org/10.1063/1.102601

[3] Liu, K., Xu, J., Yuan, T., et al. (2006) Terahertz Radiation from InAs Induced by Carrier Diffusion and Drift. Physical Review B, 73, Article ID: 155330. http://dx.doi.org/10.1103/PhysRevB.73.155330

[4] Dai, J., Xu, X. and Zhang, X.C. (2006) Detection of Broadband Terahertz Waves with a Laser-Induced Plasma in Gases. Physical Review Letters, 97, Article ID: 103903. http://dx.doi.org/10.1103/PhysRevLett.97.103903

[5] Carr, G.L., Martin, M.C., Mekinney, W.R., et al. (2002) Highpower Terahertz Radiation form Relativistic Electrons. Nature, 420, 153-156. http://dx.doi.org/10.1038/nature01175

[6] Xu, J., Yuan, T., Mickan, S., et al. (2003) Limit of Spectral Resolution in Terahertz Time-Domain Spectroscopy. Chinese Physics Letters, 20, 1266-1268. http://dx.doi.org/10.1088/0256-307X/20/8/324

[7] Kersting, R., Unterrainer, K., Strasser, G., et al. (1997) Few-Cycle T Hz Emission from Cold Plasma Oscillations. Physical Review Letters, 79, 3038-3041. http://dx.doi.org/10.1103/PhysRevLett.79.3038

[8] Qu, D., Grischkowsky, D. and Zhang, W. (2004) Terahertz Transmission Properties of Thin, Subwavelength Metallic Hole Arrays. Optics Letters, 29, 896. http://dx.doi.org/10.1364/OL.29.000896

[9] Liu, H., Chen, Y. and Zhang, X.C. (2007) Characterization of Anhydrous and Hydrated Pharmaceutical Meterials with T Hz Time-Domain Spectroscopy. Journal of Pharmaceutical Sciences, 96, 927-934. http://dx.doi.org/10.1002/jps.20782

[10] Shen, Y.C., Upadhya, P.C., Linfield, H., et al. (2003) Temperature-Dependent Low-Frequency Vibrationl Spectra of Purine and Adenine. Applied Physics Letters, 82, 2350. http://dx.doi.org/10.1063/1.1565680

[11] Kutteruf, M.R., Brown, C.M., Iwaki, L.K., et al. (2003) Terahertz Spectroscopy of Short-Chain Polypeptides. Chemical Physics Letters, 375, 337-343. http://dx.doi.org/10.1016/S0009-2614(03)00856-X

[12] Wooclward, R.M., Cole, B.E., Wallace, V.P., et al. (2002) Terahertz Pulse Imaging in Reflection Geometry of Human Skin Cancer and Skin tissue. Physics in Medicine and Biology, 47, 3853-3863.

http://dx.doi.org/10.1088/0031-9155/47/21/325 
Scientific Research Publishing (SCIRP) is one of the largest Open Access journal publishers. It is currently publishing more than 200 open access, online, peer-reviewed journals covering a wide range of academic disciplines. SCIRP serves the worldwide academic communities and contributes to the progress and application of science with its publication.

Other selected journals from SCIRP are listed as below. Submit your manuscript to us via either submit@scirp.org or Online Submission Portal.
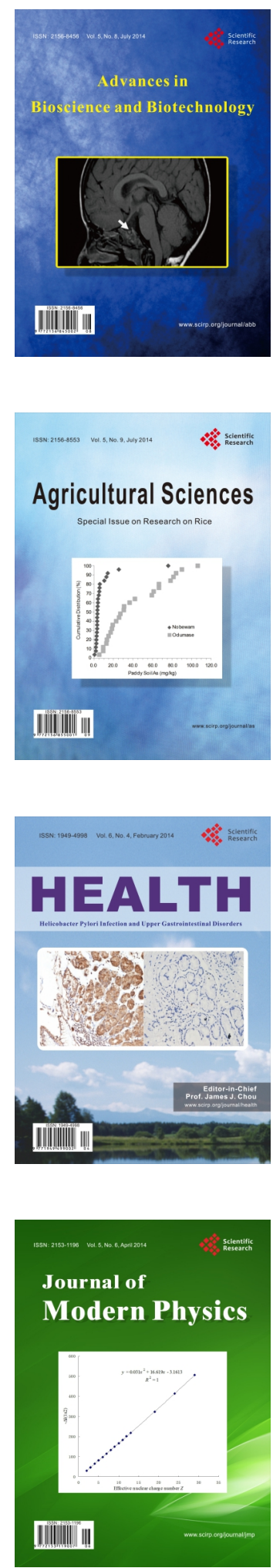
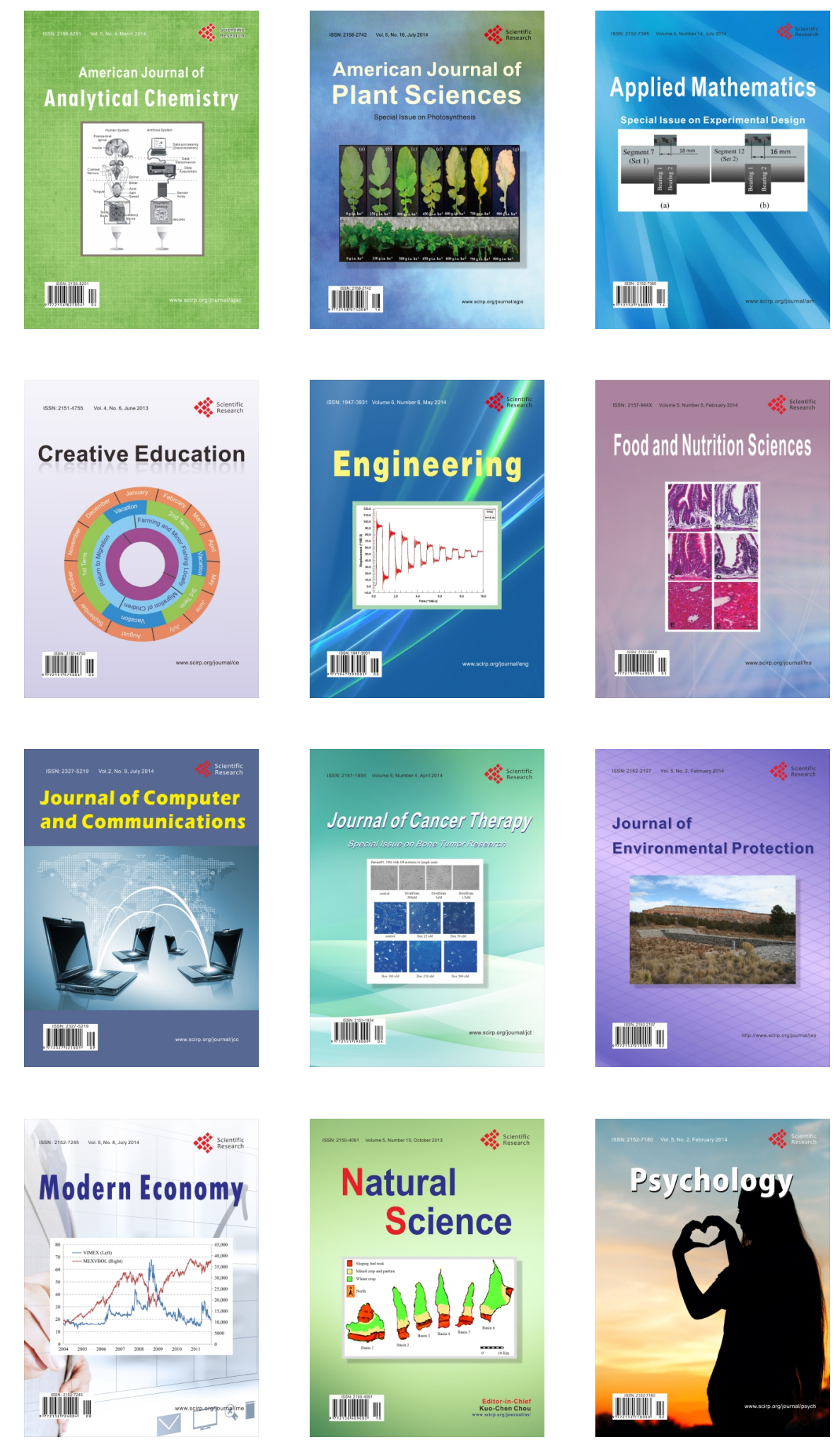